\title{
Believe normal results, but be prepared to risk that the unexpectedly abnormal is misleading
}

I met Charles the evening after a medical tribunal and we sat down to an after-dinner coffee.

'Coe,' he asked, 'what would you say to a great friend of mine aged 65 who had had a routine operation requiring a light general anaesthetic without pre-medication and a blood pressure of 110/80 throughout?'

'I would say he was a very lucky man. His blood pressure was normal but also his vascular system was very compliant as shown by the low pulse pressure. But why do you ask?'

'Well,' he said, 'his blood pressure was $230 / 130$ only one hour earlier.'

'And they went ahead without any intervention or investigation?' I said.

'Yes to the former and not quite to the latter', he replied. 'My friend was aware that he had an irrational dislike of having his blood pressure taken. The few attempts to take it in the past had produced high results except 25 years previously when the blood pressure was perfectly normal during a wisdom tooth operation. So he took the precaution of arranging for a 24-hour recording beforehand. There were several normal readings, and the ECG and chest X-ray done pre-operatively were normal.'

'A case of severe "white coat" hypertension,' I suggested.

'He wouldn't agree. He would call it "sphygmomanometer" hypertension.'

'Why?' I asked.

'He assures me that he can feel the pressure increase as the cuff tightens. Secondly, during the 24-hour monitoring, he woke up and did his blood pressure, which was clearly very low but he pressed the delete button, but on repeating the measurement the cuff went up once rather than twice. The blood pressure was 150/105, quite out of line with the other resting readings.'

'What's the point?' I asked.

'This chap is otherwise very low risk for cardiovascular disease. He feels his fluctuating blood pressure has done him no harm so far. He would rather take the unquantifiable increased risk of cerebral haemorrhage than be on tablets for the rest of his life. You might agree or disagree, but think of the consequences if the anaesthetist, who had not met my friend until an hour before the operation, had taken a different line in a less knowledgeable patient. The operation would have been deferred indefinitely because the surgeon would not go ahead under local anaesthetic. Inevitably my friend's life would have been disrupted. He would have been subjected to heavy and "failed" medication because of the difficulties in measuring his blood pressure. The anaesthetist took a wise decision contrary to all the protocols.'

'Fair enough.'

'Contrast the experience of his daughter. She had a single episode of severe but short-lived abdominal pain five weeks after her last period. She made an appointment to see her GP. He arranged for a pregnancy test which was positive and referred her to the obstetrician who saw her promptly, now ten days after the pain. When the fetal hormone level came back high, she was rung up in the middle of a dinner party at which she was hostess, and told to come to hospital immediately. An ultrasound was done which showed no abnormality. Next day she was persuaded to have a laparoscopy, although since eleven days had passed, both she and her husband would have preferred to take the risk of awaiting the outcome. It caused her considerable discomfort and worry because she was told that there was some risk to the fetus. She had a normal implantation. One clinician was prepared to take a risk. The other wasn't. Which do you think handled the case better?'

'The risk taker,' I replied.

'But had things gone wrong, would the courts have found in his favour?'

'I doubt it,' I replied, 'but perhaps you would like to hear a story where the clinical diagnosis was reasonable but the critical nearly normal test was ignored with disastrous consequence for the patient's life. At the tribunal, we saw a man who at the age of 35 in 1970 had presented with chest pain, breathlessness and wheeze. There were a few moist 
sounds in the chest, thought to be due to left ventricular failure. An ECG was said to show a coronary. A diagnosis of myocardial infarction leading to left ventricular failure was made despite transaminase levels barely above normal. For 13 years episodes of wheezing were treated as left ventricular failure, until he was seen by an excellent physician who recognised his ECG as a normal variant and successfully treated his asthma. Incidentally his transaminases were still slightly raised, in other words normal for him.'

'What is the significance of the transaminases?' Charles asked.

'They are enzymes which leak from the heart muscle when it is damaged by the coronary, but levels may be raised for other reasons. Furthermore, it is inconceivable that massive muscle damage sufficient to cause heart failure would not produce a very high transaminase level.'

\section{'And the consequences for this man's life?'}

'He was made a chronic invalid and never worked again even after the subsequent good control of his mild asthma.'

\section{'So believe your normal results?'}

'Yes,' I said, 'the next claimant drove the point home. He had gone into hospital for a knee operation five years previously and was told that a general anaesthetic was impossible because of his very bad chest with bronchitis and emphysema. He was given a spinal anaesthetic. In fact his pulmonary function tests, which are very reliable when normal, were indeed entirely normal. During our preliminary discussion, I suggested to the Chairman that this chap would be terrified if he needed an emergency operation requiring general anaesthetic. My point was proved. It transpired that he was awaiting another operation. He and his wife were extremely worried lest he be put to sleep for good.'

\section{'You mean no one had ever acted on the normal results?'}

'No,' I said. 'Presumably this chap by chance had an acute attack of wheezy bronchitis when he went in for his anaesthetic, but despite normal lungs now regards himself as a respiratory cripple.'

'So the moral of our conversation is that when you do tests you must accept the consequences. Proper management of the unexpected abnormal result may involve prudent risk taking, but act on normal results even if they conflict with your diagnosis?'

'These cases certainly support that approach.' 